\title{
BMJ Open Patient preferences for asthma management: a qualitative study
}

\author{
Christina Baggott (D) , ${ }^{1}$ Amy Chan (D) , ${ }^{2}$ Sally Hurford, ${ }^{1}$ James Fingleton (D) , \\ Richard Beasley (D) , ${ }^{1}$ Matire Harwood (D) , ${ }^{3}$ Helen K Reddel (D) , 4 \\ William Mark Magnus Levack (1) ${ }^{5}$
}

To cite: Baggott $C$, Chan A, Hurford S, et al. Patient preferences for asthma management: a qualitative study. BMJ Open 2020;10:e037491. doi:10.1136/ bmjopen-2020-037491

- Prepublication history and additional material for this paper are available online. To view these files, please visit the journal online (http://dx.doi. org/10.1136/bmjopen-2020037491).

Received 11 February 2020 Revised 01 June 2020 Accepted 02 July 2020

D) Check for updates

C Author(s) (or their employer(s)) 2020. Re-use permitted under CC BY-NC. No commercial re-use. See rights and permissions. Published by BMJ.

${ }^{1}$ Medical Research Institute of New Zealand, Wellington, New Zealand

${ }^{2}$ School of Pharmacy, The University of Auckland, Auckland, New Zealand ${ }^{3}$ Te Kupenga Hauora Maori, University of Auckland, Auckland, New Zealand

${ }^{4}$ Woolcock Institute of Medical Research, University of Sydney, Glebe, New South Wales, Australia

${ }^{5}$ Department of Medicine, University of Otago, Wellington, New Zealand

Correspondence to

Dr Christina Baggott;

christina.baggott@mrinz.ac.nz

\section{ABSTRACT}

Objective Preference for asthma management and the use of medications is motivated by the interplay between lived experiences of asthma and patients' attitudes towards medications. Many previous studies have focused on individual aspects of asthma management, such as the use of preventer and reliever inhalers. The aim of this qualitative study was to explore the preferences of patients with mild-moderate asthma for asthma management as a whole and factors that influenced these preferences.

Design A qualitative study employing qualitative descriptive analysis situated within a constructionist epistemology to analyse transcribed audio recordings from focus groups.

Setting Three locations within the greater Wellington area in New Zealand.

Participants Twenty-seven adults with self-reported doctor's diagnosis of asthma, taking short-acting betaagonists alone or inhaled corticosteroids with or without long-acting beta -agonist, who had used any inhaled asthma medication within the last month.

Results Four key areas described preferences for asthma management. Preferences for self-management: participants wanted to be in control of their asthma and developed personal strategies to achieve this. Preferences for the specific medications or treatment regimen: participants preferred regimens that were convenient and reliably relieved symptoms. Preferences for inhaler devices: devices that had dose counters and were easy to use and portable were important. Preferences for asthma services: participants wanted easier access to their inhalers and to be empowered by their healthcare providers. Participant preferences within each of these four areas were influenced by the impact asthma had on their life, their health beliefs, emotional consequences of asthma and perceived barriers to asthma management. Conclusions This study illustrates the interaction of the lived experience of asthma, factors specific to the individual, and factors relating to asthma treatments in shaping patient preferences for asthma management. This aids our understanding of preferences for asthma management from the patient perspective.

Trial registration number Australian New Zealand Clinical Trials Registry (ACTRN12619000601134).

\section{INTRODUCTION}

Living with asthma has a significant impact on patients' physical and psychological

\section{Strengths and limitations of this study}

- A broad approach to exploring the patient experience of asthma, its management and preferences for management enabled a novel analysis of patient preferences and patient experiences of asthma that influence their preferences.

- Participants were from a wide range of backgrounds, with over $50 \%$ identifying as Māori, the indigenous people of New Zealand, who have a higher prevalence of asthma and poorer asthma outcomes.

- A limitation of the study was that the majority of participants were women (23/27), which may affect the transferability of these finding to men.

well-being. ${ }^{1}{ }^{2}$ Patients describe shortness of breath, chest tightness and impact of asthma on physical activities as specific troubling symptoms. ${ }^{3}{ }^{4}$ Previous qualitative studies $^{5}$ and a meta-synthesis of qualitative studies ${ }^{6}$ found people with asthma are motivated by the interplay between lived experiences of asthma, the effect asthma has on desired activities and their attitudes towards medications. People with asthma learn to live with their asthma and adapt how they take medications and access healthcare according to their preferences and experiences.

In asthma, poor adherence to daily inhaled corticosteroids (ICS) and inappropriate reliance and overuse of short-acting beta-agonists (SABA) for symptom relief are commonplace $^{78}$ and represent significant problems as these patterns of behaviour are associated with increased symptom burden and exacerbations. ${ }^{9}$ The intermittent nature of symptoms and overestimation of asthma control ${ }^{10}$ means treatment is often suboptimal and adherence to daily preventer inhalers problematic. ${ }^{11}$ This is particularly true for indigenous peoples, ${ }^{12}$ including Māori of New Zealand ${ }^{13}$ who are disproportionately affected by asthma and adverse asthma outcomes. ${ }^{14}$

Qualitative and population-based studies show patients preferentially take reliever 
inhalers over preventer inhalers; ${ }^{75}$ this is supported by pharmacy records as more prescriptions for SABA are dispensed than ICS. ${ }^{16}$ When deciding whether to take inhalers, patients weigh-up (consciously or subconsciously) the perceived risks and benefits. ${ }^{17} 18$ Decisions relating to treatment engagement are influenced by patients' expectations and perceptions, which may be misinformed. For example, patients may have low expectations of what treatment can achieve,${ }^{19}$ have concerns about taking inhalers and use of inhaled corticosteroids or believe they are only needed intermittently. ${ }^{2021}$ In addition, there is evidence that patients would prefer to take a combined preventer and reliever inhaler in response to symptoms over a daily preventer inhaler with a reliever inhaler for symptom relief. ${ }^{22}$

Previous studies such as these have examined specific aspects of patient preferences for asthma management, but there is a paucity of information from a holistic perspective investigating patient preferences and priorities for asthma management as well as the factors that might influence preferences. To improve asthma management and outcomes it is important to understand the patient perspective for asthma management as whole as they experience it rather than individual components such as preferences for inhalers. In this qualitative study, the aim was to explore adult patients' experiences of asthma and preferences for asthma management.

\section{METHODS}

\section{Study design}

Methods and results are reported according to the Consolidated Criteria for Reporting Qualitative Research guidelines (see online supplementary file) ${ }^{23}$ A qualitative descriptive analysis situated within a constructionist epistemology was employed to describe patient preferences for treatment. ${ }^{24}$ All participants were given written information prior to attending and provided written informed consent. Characteristics of the research team are provided in the online supplementary file.

\section{Participant recruitment}

We recruited adults aged 18-75 years with a self-reported doctor's diagnosis of asthma, who had a current prescription for one or more asthma inhalers and used an inhaler for asthma within the last month. We excluded people who were not fluent in English, had other respiratory diagnoses or who had severe asthma based on the use of step 4 or 5 treatments according to the 2018 Global Initiative for Asthma (GINA) strategy. ${ }^{25}$ We undertook purposive sampling with the aim of achieving a mix of ages, gender and ethnicities; we intended to recruit Māori, at least in proportion to the current New Zealand population $(15 \%)$. We predominantly advertised via social media. Tu Kotahi Māori Asthma Trust (a Māori-led asthma service in Wellington) assisted with the recruitment of Māori participants, in line with recommendations for research with indigenous peoples. ${ }^{26}$ All participants received $50 \mathrm{NZ} \$$ for attending and could bring a support person if they signed a confidentiality agreement.

\section{Data collection}

We collected data via five one-off focus groups conducted between 7 May 2019 and 19 August 2019 at the Medical Research Institute of New Zealand (central city), an after-hours medical centre (urban site) and a community centre in an outer suburb. We used a variety of locations to increase the participation of people from diverse backgrounds. Focus groups were conducted face-to-face. Before the discussion started, participants were asked to complete a short survey collecting basic demographics, information on current inhaler use and asthma control (online supplementary file).

Focus groups were audio-recorded and transcribed verbatim. Groups lasted $60-80 \mathrm{~min}$ with two facilitators-either CB (a respiratory specialist doctor), AC (a pharmacist) or $\mathrm{SH}$ (a nurse)-experienced in qualitative methodologies and began with an introduction to the research. A discussion guide was used, developed prior to the commencement of the study (online supplementary file) informed by the study aims, review of the literature on patient preferences for asthma management, beliefs about asthma medications and the Necessities Concerns Framework proposed by Horne et al. ${ }^{27} \mathrm{MH}$ provided a review of the discussion guide from a Māori perspective. The discussion was semi-structured, between participants with prompts and questions from facilitators. The discussion guide was iterated as appropriate based on preliminary analysis of data from preceding groups. Focus groups continued until thematic saturation was achieved-when two groups had been conducted with no new themes emerging. Brief notes were made during the group, and $\mathrm{CB}$ reflected on each group afterwards. For participants who requested it when giving consent, a transcript of their own data were provided, but none requested alterations.

\section{Data analysis}

Descriptive statistics summarise information on demographics, asthma control and medication use. NVivo V.12 was used for management and coding of the qualitative data. Thematic analysis was used to analyse the data, ${ }^{28}$ themes were derived from the data. Initial coding was done on a line-by-line basis with an iterative process of reading, reviewing and refining themes and subthemes to develop overarching concepts. All the data were coded by $\mathrm{CB}$ with AC peer coding $20 \%$ of the data. Emerging themes and concepts were discussed and iterated following each focus group between $\mathrm{CB}, \mathrm{AC}$ and $\mathrm{WL}$ with MH providing the Kaupapa Māori research oversight. ${ }^{26}$ The supplement includes additional quotes in (online supplementary tables S1-S8).

\section{Patient and public involvement}

There was no public or patient engagement in the study development or design. Participants were given the 
opportunity to edit their transcripts and provided with a summary of the results.

\section{RESULTS}

\section{Participant characteristics}

We held five focus groups, each with three to eight participants (total $\mathrm{n}=27$ ), mean age 37 years; $56 \%$ of participants identified as Māori and participated across all focus groups, $56 \%$ had uncontrolled asthma as per GINA asthma symptom control, and $70 \%$ reported urgently visiting their doctor at least once in the last year for asthma (table 1). Most participants (59\%) were taking ICS/longacting beta-agonist (LABA) maintenance therapy with a SABA reliever (table 2), corresponding to step 3 of thencurrent New Zealand asthma guidelines. ${ }^{29}$

\section{Overview of findings}

Participants' descriptions of their experience of asthma and its management comprised four factors: (1) the impact of asthma on life, (2) emotional consequences of asthma, (3) health beliefs and (4) perceived barriers to asthma management. Preferences for asthma management fell into four key areas: (1) preferences for selfmanagement, (2) specific preferences for medications or regimens, (3) preferences for inhaler devices and (4) preferences for asthma services.

\section{Patient experiences of asthma and its management \\ Impact of asthma on life}

Asthma had far-reaching effects on participants' lives. Physical experiences of asthma symptoms were forefront in all participants' narratives. Breathlessness was the most common symptom and had the greatest impact. Night waking due to asthma and cough had a greater impact on participant's lives than other asthma symptoms such as wheeze, chest tightness and sputum. Asthma frequently limited physical exertion such as walking up inclines and restricted participation in sports.

Asthma affects me from like my day to day with like just a lot of the simple things that a lot of people can do and almost they take for granted... I used to always really like to play sport, I played cricket and soccer, but I had to give it up because it just got so bad that I couldn't even walk without it just flaring up and me almost conking out on the floor. (G5P2)*

* Following each quote is the participants' focus group number and participant number.

Participants' perception of their asthma severity ranged from very mild to 'nowhere near cope-able' (G1P1). Asthma could flare up very suddenly. Experiences of asthma flare-ups had short-term effects from the impact of worsening symptoms but also longer-term effects as some participants experienced worsening symptoms for several months that they struggled to control.

One minute you're standing up and the next minute you're on the floor. (G3P6)

\begin{tabular}{|c|c|}
\hline Characteristics & $\mathrm{N}=27$ \\
\hline \multicolumn{2}{|l|}{ Sex N (\%) } \\
\hline Female & $23(85)$ \\
\hline Male & $4(15)$ \\
\hline \multicolumn{2}{|l|}{ Age-years } \\
\hline Mean & 37.1 (15.3) \\
\hline Range & $19-67$ \\
\hline Age at asthma diagnosis-years & $8.8(12.0)$ \\
\hline \multicolumn{2}{|l|}{ Ethnicity N (\%) } \\
\hline Asian & $2(7)$ \\
\hline Māori & $15(56)$ \\
\hline (Māori+another ethnic identity) & $11(73)$ \\
\hline NZ European & $10(37)$ \\
\hline \multicolumn{2}{|l|}{ Highest level of education N (\%) } \\
\hline High School & $3(11)$ \\
\hline Some college & $8(30)$ \\
\hline Three or more years at college or university & $16(59)$ \\
\hline \multicolumn{2}{|l|}{ Smoking status N (\%) } \\
\hline Current smoker & $8(30)$ \\
\hline Ex-smoker & $9(33)$ \\
\hline Never smoker & $10(37)$ \\
\hline \multicolumn{2}{|c|}{$\begin{array}{l}\text { Number of urgent visits to a doctor for asthma } \\
\text { in the last year } \mathrm{N}(\%)\end{array}$} \\
\hline 0 & $8(30)$ \\
\hline 1 & $9(33)$ \\
\hline 2 & $6(22)$ \\
\hline$\geq 3$ & $4(15)$ \\
\hline
\end{tabular}

GINA 2018 level of asthma symptom control

$\mathrm{N}(\%)$

$\begin{array}{lr}\text { Well controlled } & 3(11) \\ \text { Partly controlled } & 9(33) \\ \text { Uncontrolled } & 15(56) \\ \text { Current asthma medication use N (\%) } & \\ \text { SABA monotherapy } & 4(15) \\ \text { ICS +SABA } & 3(11) \\ \text { ICS/LABA (SMART therapy) } & 4(15) \\ \text { ICS/LABA+SABA } & 16(59)\end{array}$

Data are means (SD) unless otherwise stated. See Beasley $R^{29}$ for NZ asthma guidelines that applied at the time of the focus groups. GINA, Global Initiative for Asthma; ICS, inhaled corticosteroid; LABA, long acting beta-agonist; NZ, New Zealand; SABA, short acting beta-agonist; SMART, single maintenance and reliever therapy.

Asthma affected the participants' ability to interact with their peer group and engage in social activities and contributed to frustration and isolation. Asthma had a direct monetary cost, through the costs of general practictioner (GP) appointments and repeat prescriptions, and 
Table 2 Inhalers used in the last 3 months and patient reported reasons for use

\begin{tabular}{llllll}
\hline & & \multicolumn{4}{c}{ Reason for taking the inhaler N (\%) } \\
\cline { 3 - 6 } $\begin{array}{l}\text { Inhalers used in the last 3 months } \\
\text { N (\%) }\end{array}$ & & Relieve symptoms & $\begin{array}{l}\text { Prevent } \\
\text { symptoms }\end{array}$ & Both & Unsure \\
\hline Salbutamol & $21(77)$ & $15(71)$ & 0 & $5(24)$ & $1(5)$ \\
Terbutaline & $2(7)$ & $2(100)$ & 0 & 0 & 0 \\
Salmeterol & $1(4)$ & 0 & $1(100)$ & 0 & 0 \\
Fluticasone propionate & $5(19)$ & 0 & $4(80)$ & $1(20)$ & 0 \\
Beclomethasone & $1(4)$ & 0 & $1(100)$ & 0 & 0 \\
Fluticasone propionate/salmeterol & $6(22)$ & $2(33)$ & $3(50)$ & $1(17)$ & 0 \\
Budesonide/formoterol & $14(52)$ & $1(7)$ & $4(29)$ & $9(64)$ & 0 \\
Fluticasone furoate/vilanterol & $2(7)$ & $1(50)$ & $1(50)$ & 0 & 0
\end{tabular}

some felt asthma negatively impacted on employment opportunities.

When I go for a job I don't put down I'm an asthmatic, cause otherwise they don't want you. (G4P4)

Asthma treatments interfered with participants' lives, including time taken to use inhalers properly, medication side effects, numbers of medications and inconvenience.

\section{Emotional consequences of asthma}

Asthma flare-ups were frightening experiences; some were severe enough that the patients feared they might die. Anxiety about timely access to emergency help influenced behaviour and life choices, such as avoiding certain activities like hiking. Participants discussed people they knew or had read about in the media who died from asthma, which affected how they felt about asthma and its treatment.

Cause I thought I was going to die and then my kids are standing there going Mama going to die, you know, and then I come up with all these beautiful words. (G4P5)

The unpredictable and variable nature of symptoms led to feelings of fear, worsened by concerns about access to reliever inhalers or reliever inhalers may not work when symptoms were severe.

I was so heavily reliant on [salbutamol] being my saviour when I needed it. And when I would run out of it, I would have this massive rush of, oh crap, what's gonna happen if I have an asthma attack? (G2P1)

When discussing the interplay of asthma and mental health, some participants acknowledged having mental health problems because of their asthma experiences, or mental health problems could lead to worsening asthma. Anxiety was the most commonly discussed mental health problem; pre-existing anxiety was worsened by asthma symptoms, use of SABA, or by concerns about access to medications. For some, weight gain from oral steroids contributed to eating disorders.
It's like a feedback loop, your asthma causes your anxiety and your anxiety causes your asthma. (G2P3)

Health beliefs

Participants' beliefs about benefits and the perceived necessity of preventer and reliever inhalers, together with personal experiences, shaped their management strategies. Most participants admitted to episodes of poor adherence to preventer inhalers, and some had stopped them completely. Some felt their preventer inhalers were necessary and noticed the benefits of using them, while others preferred to live life without them-considering preventers optional. Some participants doubted the efficacy of preventer inhalers and admitted to not using them at all. Not feeling the medication working immediately or being required to take it even if they did not have asthma symptoms reinforced these perceptions.

Yeah, I don't really use it [the preventer inhaler] though. I think it's probably because I think it's not going to work. (G1P3)

In contrast, participants did not express doubts about the necessity of their reliever inhalers. Many participants expressed some scepticism about medicines in general, discussing concerns about medications or the need to minimise the use of medicines altogether. They worried that overuse of preventer and reliever inhalers could cause them to become addicted to or dependent on their medications or had concerns about overdosing.

I try and make my body starve a little bit [i.e. take less medications], cause of the toxins I've been on. Cause I class it [asthma preventer and reliever medications] as toxin. (G4P5)

\section{Barriers to asthma management}

Barriers to managing asthma were widely discussed. Some participants described a lack of understanding or education about asthma as a barrier to managing asthma. Interactions with healthcare professionals did not always meet their expectations or healthcare needs-and asthma and 
its treatments were not appropriately explained. Participants wanted a deeper understanding of asthma and their medications and wanted to feel their doctor had assessed their asthma and response to treatment properly.

For my asthma inhalers I find that I don't know whether I'm taking my asthma inhaler right because my doctor never asked me anything about it. It's just like, here's your repeat prescription, there you go. It's not an in-depth conversation. (G1P1)

Most participants had experienced conflict with healthcare professionals over their asthma management. When they sought help for worsening asthma, some felt they were being judged, they were overreacting or responsible for their situation.

I went and got an emergency inhaler and was treated at the pharmacy like I should be in jail for even asking for an emergency [reliever inhaler]. (G2P1)

There were instances where participants described conflicting advice or misinformation from healthcare professionals.

Participants felt family and friends often did not understand asthma properly, including it could be life threatening. This led to feelings of embarrassment about their symptoms or using asthma inhalers in front of others, which affected social interactions and delayed use of reliever inhalers.

I think asthma is tough in terms of believability because people who don't know what to look for don't believe you until you are literally on the floor because you can't breathe. (G2P3)

\section{Patient preferences for asthma management \\ Asthma self-management}

Participants wanted to be in control of their asthma and wanted it not to prevent them from doing things that I want to' (G2P4). They developed their own strategies to feel in control. Routine was a positive strategy, which promoted regular use of preventers whereas lack of routine and forgetfulness contributed to erratic use of preventer inhalers. Access to inhalers and control over inhaler supplies were important to participants' management strategies, and included stockpiling inhalers, using out-of-date inhalers, or borrowing them from others.

Running out of inhalers or restricted access due to dispensing rules at pharmacies (online supplementary file) led to anxiety and worsening asthma in some participants. Some participants responded by 'training' their healthcare providers to improve their access to inhalers. For some written asthma action plans were a useful aid to managing asthma, which gave them legitimacy when seeking help for uncontrolled asthma. However, others did not like these plans because they were complicated or difficult to follow.

Most participants recognised their specific asthma triggers such as animals, perfume or viral infections, and would limit their exposure to triggers or adjust their treatments.

\section{Regimen and medication preferences}

Participants wanted a treatment that would get rid of my asthma' (G1P7); some felt that preventing or relieving asthma symptoms did not really count as treatment' because it did not 'cure' it. They valued medicines that had observable effects, particularly in times of worsening asthma. This included combination ICS/LABA inhalers that ameliorated symptoms quickly, although many said SABAs were their best treatment option because of their obvious and reliable effects.

That's what I like about [budesonide-formoterol], you take it when you're wheezy and you're not wheezy anymore, it's great. (G3P7)

Trust in the effectiveness of asthma medications was important. Participants trusted reliever inhalers they had used as children, could feel working or inhalers that gave some physical sensation when used. The taste of inhalers, even if unpleasant, reassured participants that 'something's gone in' (G5P1). Lack of a physical sensation meant some questioned if the inhaler had actuated properly, or if the medication was working. Participants did not like side effects from their inhalers, for example, shakes'from SABAs or oral thrush from ICS.

Some participants described high use of SABA inhalers, driven by their personal strategies for managing worsening asthma and beliefs regarding its effectiveness for symptom relief, for example, 30 puffs for an attack or an entire inhaler (200 doses) in a week.

Yeah, so I always make sure I've got three of those [reliever inhalers]. Cause when it's really bad I can go through an inhaler in a week. (G5P1)

Participants wanted convenient, simple treatments. Some found their treatment regimens confusing and were not sure when or how to use their medications. Participants liked adjusting their medications themselves; some were on a regimen that allowed increased doses of ICS-formoterol in response to symptoms (single maintenance and reliever therapy (SMART)), while others had adapted their treatments themselves by increasing or decreasing use of preventer and reliever inhalers in response to different situations. Being able to use a preventer only when needed was considered preferable. Many described wanting to reduce their use of medication, particularly preventer inhalers.

Taking preventers every day was 'annoying'; participants felt 'put-off' by a two times per day prescription. One time a day use was easier to remember and was preferred, particularly if it meant reliever inhalers were not needed for the rest of the day.

The ideal inhaler for me would just be a once a day and it takes you throughout the whole day and night, you don't need to worry about it again. (G1P1) 


\section{Device preferences}

Participants liked inhaler devices that were small, easy to use, portable and would fit in a pocket. Some were happy to use spacers, whereas others were not and valued inhalers which did not need a spacer. They wanted their inhalers to contain more doses and last longer. A dose counter (not included on some preventer and reliever inhalers in New Zealand) was important for all participants because it allowed them to plan when to get another inhaler and avoid using empty inhalers.

If you take pills you can see how many you've had, but with an inhaler it's just like all of a sudden there's none left. (G4P2)

There was variation in preference for dry powder inhalers or metered dose inhalers. Many didn't like the noise of metered dose inhalers because it drew attention to them taking the inhaler. Participants had environmental concerns about inhaler devices, particularly the quantity of plastic generated and wanted inhalers to be recycled or refillable.

\section{Preferences for services}

Participants wanted a positive relationship with healthcare providers; however, many described negative interactions such as being made to feel shame' or not receiving a warm reception' when seeking care for asthma or felt they were 'getting a lecture'. When they went to see healthcare providers, participants wanted to be taken seriously, and feel their asthma and treatment had been properly reviewed. They wanted to be empowered by health professionals to manage their asthma.

I want when I go to a doctor or to ED [emergency department] or somewhere, I want to stop feeling shame. (G3P6)
Participants wanted their inhalers to be easier to obtain, and for there to be less 'red tape'. They felt obtaining asthma inhalers was more difficult than other prescription medications, and the system of organising and collecting repeat prescriptions confusing and unfair. Some described being limited to one preventer inhaler at a time, but were given several SABA inhalers. This, combined with difficulty getting to see their doctor or having to wait for repeat prescriptions meant some had times without inhalers. They wanted the frequency of routine appointments for repeat prescriptions and medications reduced and to be dispensed more inhalers each time. They wanted the process of going for a review and collecting prescriptions and medications to be streamlined' and flexible.

Gosh, for something that assists your breathing, it [inhalers] should be more accessible. (G3P8)

An overview of patient experiences and patient preferences for asthma management, is given in table 3 .

\section{DISCUSSION}

This qualitative study explored patient experiences of asthma and its treatment and provides an overarching narrative of the patient experience of asthma and preferences for asthma management (table 3). Patient experiences of asthma influenced their preferences for the different aspects of asthma management in varying degrees.

We found that there was no single version of what 'ideal asthma management' was. However, there was general agreement that less frequent use of preventer medications was preferable. Participants wanted to feel their medications working quickly, have control over their treatment

Table 3 Overview of factors influencing patient preferences for key areas of asthma management

\section{Patient experiences that affected preferences}

1.Impact of asthma on the For example, experience of symptoms, restriction of activity, flare-ups, interactions with
patient's life

2.Emotional consequences of asthma

\section{Health beliefs \\ 4.Barriers to asthma management \\ 1.Self-management \\ 2.Regimen and medication preferences}

3.Device preferences
For example, frightening asthma experiences, concern about access to medications and emergency services, awareness of deaths due to asthma, interplay between asthma and mental health.

For example, beliefs about benefits and necessity of inhalers and concerns about medications.

For example, lack of understanding and education, negative interactions with healthcare professionals and embarrassment.

\section{Key areas of patient preference for asthma management}

For example, personal strategies, control over inhaler supplies, management of triggers and written asthma action plans.

For example, preference for medications with observable effects, trust in inhalers, convenience and flexibility to adjust therapy.

For example, small, portable devices, dose counter and environmentally friendly.

For example, positive relationship with healthcare providers and easy to obtain inhalers. 
and be able to adjust it as necessary. They wanted a dose counter on all their inhalers to let them know how much medication remained and wanted barriers to timely and accessible healthcare removed. From the participants' perspective, management of asthma in clinical practice could be improved if clinicians acknowledged how asthma impacts on their life, where possible tailored treatment regimens to their preferences and empowered them to manage their asthma.

Consistent with previous qualitative studies, shortness of breath was a distressing symptom with a substantial impact on the participants' lives. ${ }^{4}$ Asthma led to activity limitation, but participants adapted by changing their activities or normalising their experience. ${ }^{30}$ Similar to other qualitative studies, ${ }^{31}$ we found fear was a common part of participants' asthma narrative. In our study, fear was linked to previous experiences of uncontrolled asthma or anxieties about availability or effectiveness of asthma medications, for some participants anxiety and asthma were closely interrelated. Similar to previous research, ${ }^{32}$ our participants had a range of health beliefs surrounding their preventer inhalers; however, they did not doubt the necessity of their reliever inhalers. ${ }^{20}$ Barriers to asthma management led to participants feeling they did not have the necessary control over their management. This study fills an important evidence gap about what patients themselves perceive as ideal ways of managing asthma, and their own priorities for asthma management, an understanding of which is essential to improving asthma outcomes.

We did not anticipate the negative reactions from healthcare professionals that many participants described experiencing when seeking care for their asthma, or the difficulty they had in obtaining inhalers for their asthma (additional quotes are given in online supplementary tables S4 and S8 in the online supplementary appendix). These reactions were not confined to one professional group and included doctors, nurses, pharmacists and paramedics. This was an issue that was spontaneously bought up in all focus groups across ages and ethnicities. While it is possible this issue is unique to New Zealand and could be related to the national dispensing regulations, it is an issue which requires further investigation to ascertain if it is widespread and whether, as our participants described, it negatively impacts on asthma management.

Use of focus groups to collect data is a strength of this study, as it led to a discussion between the participants rather than directed by the researchers. This generated rich, naturalistic data and some insights that the research team did not fully anticipate. Use of thematic analysis was appropriate given our research question, and themes were explored as they emerged. Peer coding and collaborative approach to analysis enhances the validity of the findings. Transcription verbatim and use of qualitative software to code the data enhanced the reliability. We achieved data saturation after the third focus group; then conducted two subsequent groups to check this assumption. Participants were recruited predominantly through advertising on social media so were not restricted to patients attending a clinic or GP practice. Holding groups in several locations increased the diversity of our sample.

We used purposeful sampling; however, despite efforts to recruit male participants, the majority of our participants $(85 \%)$ were women. This is a limitation of our study, which may affect the generalisability of our results. Nonetheless, the men in our sample did not express notably different opinions from the women. In other studies, beliefs around medicines and illness perceptions, often described in terms of necessities and concerns, ${ }^{27}$ predicted poor adherence more robustly than any particular sociodemographic or clinical factors, ${ }^{17}$ suggesting asthma management is not a strongly gendered issue. Other limitations include there was no public or patient engagement in the study design, and only $20 \%$ of the data were peer coded; however, the data were widely discussed, and coding reviewed with in the research team. There may have been a potential for researcher professional bias. However, we attempted to limit this through the use of a multidisciplinary team, some of whom have a lived experience of asthma, and application of self-reflective practices through memo writing and team debriefing. Finally, caution should be taken when generalising the findings of qualitative research.

While we collected data on current asthma treatments and level of asthma control we did not systematically collect data on whether the participants had a personalised asthma action plan or were under the care of a specialist respiratory physician both of which may have influenced preferences for asthma services and experiences of asthma self-management. However, as we excluded people who were taking medications at step $4 / 5$ asthma treatments in a New Zealand context this means that most patients under the care of a respiratory specialist would have been excluded as most patients with asthma are under the care of their GP unless they require treatments such as maintenance oral steroid or biological agents.

We specifically intended to recruit Māori, at least in proportion to the current New Zealand population $(15 \%)$ and were more than successful as over $50 \%$ of our participants identified as Māori. Our aim was to explore patients' experience of asthma and their preferences for asthma management as an overarching concept, therefore, we did not analyse the data separately for Māori and non- Māori participants, in line with comparable qualitative research. ${ }^{33}$ It is relevant, however, that the results reflect similar themes of self-management and health service obstacles described by other Indigenous and nonindigenous peoples living with asthma. ${ }^{34} 35$

Future studies exploring patient preferences for asthma management in broader populations, in combination with the insights from qualitative studies would provide a deeper understanding of the management strategies that patients prefer. In clinical practice, asthma management could be improved through a better understanding of patient preferences and perspective on treatment. 
In conclusion, the findings from this study suggest that the impact of asthma on life, health beliefs, emotional consequences and barriers to asthma management influence patients' preferences for different aspects of asthma management. This aids our understanding of asthma management from the patient perspective. This information can be used to improve shared decision-making, help patients navigate through asthma services, identify appropriate treatments and empower them to have ownership and control over their asthma management.

Acknowledgements We are grateful to the participants for their time and taking part in the study. We would like to thank Cheryl Davies and TJ Ranga from Tu Kotahi Māori Asthma Trust for their help recruiting Māori participants, and research for life for providing part of the funding towards this study (https://researchforlife.org.nz).

Contributors CB, HKR, JF, RB and WMML conceived the idea. The study protocol was written by $\mathrm{CB}, \mathrm{AC}, \mathrm{JF}, \mathrm{HKR}$ and WMML in consultation with MH on Māori perspectives. $\mathrm{CB}, \mathrm{AC}$ and $\mathrm{SH}$ collected the data. Transcription was conducted by a commercial company, all transcript were checked against the audio recordings by $\mathrm{CB}$. Coding was undertaken by $\mathrm{CB}$ and $\mathrm{AC}$. Data analysis and interpretation were undertaken by $\mathrm{CB}, \mathrm{AC}, \mathrm{MH}, \mathrm{HKR}$ and WMML. All authors had full access to the audio files, transcripts and coding. CB and WMML wrote the first draft of the manuscript, and all authors contributed to the final version.

Funding The study was funded by a grant from Research for Life (2019/300) and the study sponsor the Medical Research Institute of New Zealand (MRINZ). The MRINZ receives Independent Research Organisation funding from the Health Research Council of New Zealand.

Competing interests CB reports personal fees from AstraZeneca and Novartis. AC reports grants from Maurice and Phyllis Paykel Trust, Innovate UK, NZPERF, U21, A+Charitable Trust and consultancy fees from Janssen-Cilag, and Spoonful of Sugar Ltd. JF reports grants from Health Research Council of New Zealand, AstraZeneca, GlaxoSmithkline and Genentech; and personal fees and non-financial support from AstraZeneca, GlaxoSmithkline and Boehringer Ingleheim. RB reports grants from Health Research Council of New Zealand, Genentech, AstraZeneca, GlaxoSmithKline; and personal fees from AstraZeneca, Avillion and Theravance. $\mathrm{MH}$ reports grants from Health Research Council of New Zealand. HR reports grants from GlaxoSmithKline, AstraZeneca and Novartis; personal fees from AstraZeneca, GlaxoSmithKline, Merck, Novartis, Teva, Sanofi Genzyme and Boehringer Ingelheim; and is chair of the Global Initiative for Asthma scientific committee.

Patient consent for publication Not required.

Ethics approval The study had ethical approval from the Central Health and Disability Ethics Committee (19/CEN/52).

Provenance and peer review Not commissioned; externally peer reviewed.

Data availability statement Data are available upon reasonable request. Deidentified access to transcripts from focus groups will be shared 2 years after article publication with no end date. These data will be available to researchers who provide a methodologically sound proposal for the purposes of achieving specific aims outlined in that proposal. Proposals should be directed to the study sponsor the Medical Research Institute of New Zealand by emailing Prof Richard Beasley ( richard.beasley@mrinz.ac.nz). Requests to access data to undertake hypothesis driven research will not be unreasonably withheld. To gain access, data requesters will need to sign a data access agreement and to confirm that data will only be used for the agreed purpose for which access was granted.

Open access This is an open access article distributed in accordance with the Creative Commons Attribution Non Commercial (CC BY-NC 4.0) license, which permits others to distribute, remix, adapt, build upon this work non-commercially, and license their derivative works on different terms, provided the original work is properly cited, appropriate credit is given, any changes made indicated, and the use is non-commercial. See: http://creativecommons.org/licenses/by-nc/4.0/.

\section{ORCID iDs}

Christina Baggott http://orcid.org/0000-0002-3581-4472

Amy Chan http://orcid.org/0000-0002-1291-3902

James Fingleton http://orcid.org/0000-0001-9148-196X

Richard Beasley http://orcid.org/0000-0003-0337-406X

Matire Harwood http://orcid.org/0000-0003-1240-5139
Helen K Reddel http://orcid.org/0000-0002-6695-6350

William Mark Magnus Levack http://orcid.org/0000-0001-6631-908X

\section{REFERENCES}

1 O'Conor R, Martynenko M, Gagnon M, et al. A qualitative investigation of the impact of asthma and self-management strategies among older adults. J Asthma 2017;54:39-45.

2 Oncel S, Ozer ZC, Yilmaz M. Living with asthma: an analysis of patients' perspectives. J Asthma 2012;49:294-302.

3 Globe G, Martin M, Schatz M, et al. Symptoms and markers of symptom severity in asthma-content validity of the asthma symptom diary. Health Qual Life Outcomes 2015;13:21-9.

4 Svedsater $\mathrm{H}$, Roberts J, Patel C, et al. Life impact and treatment preferences of individuals with asthma and chronic obstructive pulmonary disease: results from qualitative interviews and focus groups. Adv Ther 2017;34:1466-81.

5 Steven K, Morrison J, Drummond N. Lay versus professional motivation for asthma treatment: a cross-sectional, qualitative study in a single Glasgow general practice. Fam Pract 2002;19:172-7.

6 Pickles K, Eassey D, Reddel HK, et al. "This illness diminishes me. what it does is like theft": aqualitative meta-synthesis of people's experiences of living with asthma. Health Expect 2018;21:23-40.

7 Partridge MR, van der Molen T, Myrseth S-E, et al. Attitudes and actions of asthma patients on regular maintenance therapy: the INSPIRE study. BMC Pulm Med 2006;6:1-9.

8 Erickson SR, Coombs JH, Kirking DM, et al. Compliance from selfreported versus pharmacy claims data with metered-dose inhalers. Ann Pharmacother 2001;35:997-1003.

9 Engelkes M, Janssens HM, de Jongste JC, et al. Medication adherence and the risk of severe asthma exacerbations: a systematic review. Eur Respir J 2015;45:396-407.

10 Price D, Fletcher M, van der Molen T. Asthma control and management in 8,000 European patients: the recognise asthma and link to symptoms and experience (realise) survey. NPJ Prim Care Respir Med 2014;24:14009.

11 Al-kalemji A, Johannesen $\mathrm{H}$, Dam Petersen $\mathrm{K}$, et al. Asthma from the patient's perspective. J Asthma 2014;51:209-20.

12 Jenkins CR, Chang AB, Poulos LM, et al. Asthma in Indigenous Australians: so much yet to do for Indigenous lung health. Med $J$ Aust 2009;190:530-1.

13 Jones B, Ingham TR, Cram F, et al. An Indigenous approach to explore health-related experiences among Māori parents: the Pukapuka Hauora asthma study. BMC Public Health 2013;13:228.

14 Barnerd DLT, Zhang J. The impact on respiratory disease in New Zealand: 2016 update - Asthma + Respiratory Foundation NZ, 2017.

15 Cole S, Seale C, Griffiths C. 'The blue one takes a battering' why do young adults with asthma overuse bronchodilator inhalers? A qualitative study. BMJ Open 2013;3:e002247.

16 Laforest L, Licaj I, Devouassoux G, et al. Prescribed therapy for asthma: therapeutic ratios and outcomes epidemiology and research methodology in primary care. BMC Fam Pract 2015;16.

17 Horne R, Weinman J. Patients' beliefs about prescribed medicines and their role in adherence to treatment in chronic physical illness. $J$ Psychosom Res 1999;47:555-67.

18 Horne R, Chapman SCE, Parham R, et al. Understanding patients' adherence-related beliefs about medicines prescribed for longterm conditions: a meta-analytic review of the Necessity-Concerns framework. PLoS One 2013;8:e80633.

19 Haughney J, Barnes G, Partridge M, et al. The living \& breathing study: a study of patients' views of asthma and its treatment. Prim Care Respir J 2004;13:28-35.

20 Lycett H, Wildman E, Raebel EM, et al. Treatment perceptions in patients with asthma: synthesis of factors influencing adherence. Respir Med 2018;141:180-9.

21 Bender BG, Bender SE. Patient-identified barriers to asthma treatment adherence: responses to interviews, focus groups, and questionnaires. Immunol Allergy Clin North Am 2005;25:107-30.

22 Baggott C, Reddel HK, Hardy J, et al. Patient preferences for symptom-driven or regular preventer treatment in mild to moderate asthma: findings from the practical study, a randomised clinical trial. Eur Respir J 2020;55:1902073.

23 Tong A, Sainsbury P, Craig J. Consolidated criteria for reporting qualitative research (COREQ): a 32-item checklist for interviews and focus groups. Int J Qual Health Care 2007;19:349-57.

24 Sandelowski M. Focus on research methods: whatever happened to qualitative description? Res Nurs Heal 2000;23:334-40.

25 Global Initiative for Asthma. Global strategy for asthma management and prevention, 2018. Available: www.ginasthma.org 
26 Reid P, Paine S-J, Curtis E, et al. Achieving health equity in Aotearoa: strengthening responsiveness to Māori in health research. $N Z$ Med $J$ 2017;130:96-103.

27 Horne R, Weinman J. Self-regulation and self-management in asthma: exploring the role of illness perceptions and treatment beliefs in explaining non-adherence to preventer medication. Psychol Health 2002;17:17-32.

28 Braun V, Clarke V. Using thematic analysis in psychology. Qual Res Psychol 2006;3:77-101.

29 Beasley R, Hancox RJ, Harwood M, et al. Adult asthma guidelines. N Z Med J 2016;129:83-102.

30 Ulrik CS, Backer V, Søes-Petersen U, et al. The patient's perspective: adherence or non-adherence to asthma controller therapy? J Asthma 2006;43:701-4

31 Foster JM, McDonald VM, Guo M, et al. "I have lost in every facet of my life": the hidden burden of severe asthma. Eur Respir J 2017;50:1700765-11.
32 Miles C, Arden-Close E, Thomas M, et al. Barriers and facilitators of effective self-management in asthma: systematic review and thematic synthesis of patient and healthcare professional views. NPJ Prim Care Respir Med 2017;27:1-21.

33 Muller D, Paine S-J, Wu LJ, et al. "Their sleep means more harmony": maternal perspectives and experiences of preschoolers' sleep in ethnically and socioeconomically diverse families in Aotearoa/New Zealand. Qual Health Res 2019;29:2023-34.

34 Levack WM, Jones B, Grainger R, et al. Whakawhanaungatanga: the importance of culturally meaningful connections to improve uptake of pulmonary rehabilitation by Māori with COPD - a qualitative study. Int J Chron Obstruct Pulmon Dis 2016;11:489-501.

35 Ratima MM, Fox C, Fox B, et al. Long-term benefits for Mäori of an asthma self-management program in a Mäori community which takes a partnership approach. Aust N Z J Public Health 1999;23:601-5. 